BULLETIN Bulletin hispanique

HISPANIQUE Université Michel de Montaigne Bordeaux

$110-2 \mid 2008$

Varia

\title{
In virum mutata est Transexualidad en la Europa de los siglos XVI y XVII
}

María Jesús Zamora Calvo

\section{(2) OpenEdition}

Journals

Édition électronique

URL : http://journals.openedition.org/bulletinhispanique/748

DOI : 10.4000/bulletinhispanique. 748

ISSN : 1775-3821

Éditeur

Presses universitaires de Bordeaux

Édition imprimée

Date de publication : 1 décembre 2008

Pagination : 431-447

ISBN : 978-2-86781-543-0

ISSN : 0007-4640

Référence électronique

María Jesús Zamora Calvo, «In virum mutata est Transexualidad en la Europa de los siglos XVI y XVII », Bulletin hispanique [En ligne], 110-2 | 2008, document 2, mis en ligne le 01 décembre 2011, consulté le 19 avril 2019. URL : http://journals.openedition.org/bulletinhispanique/748 ; DOI : 10.4000/bulletinhispanique.748 


\title{
In virum mutata est Transexualidad en la Europa de los siglos XVI y XVII
}

\author{
María Jesús Zamora Calvo \\ Universidad Autónoma - Madrid
}

L'objet de cet article est l'étude de la transsexualité dans un type de discours bien précis des Siècles d'Or: les récits insérés à l'intérieur des traités de magie. Des auteurs comme le père Martín del Río, le frère Francisco María Guaccio, le père Nieremberg, Ambroise Paré ont étudié la mutation du sexe féminin en sexe masculin et vice versa comme un phénomène absolument naturel auquel ne participent en rien ni sorcellerie ni démonologie.

Este artículo se centra en el estudio de la transexualidad en los Siglos de Oro en un discurso muy concreto: el de los cuentos insertos dentro de tratados de magia. Autores como el padre Martín del Rio, fray Francisco María Guaccio, el padre Nieremberg, Paré, etc. investigaron la mutación del sexo femenino en masculino y viceversa como un fenómeno que se produce de forma natural, sin que la brujería ni la demonología tuvieran que ver.

This article aims at studying transsexuality in a very precise type of discourse during the Golden Centuries: stories inserted inside treatises on magic. Authors like Father Martin del Rio, Fra Francisco Maria Guaccio, Father Nieremberg, Ambroise Paré etc, investigated the mutation of the female sex into male and vice versa as an absolutely natural phenomenon, which neither witchcraft nor demonology were involved in.

Mots clés: Transsexualité - Récits - Traités de magie - Littérature du Siècle d'Or.

$B H i$, Tome 110, n 2 - décembre 2008 - p. 431 à 447. 
...en la portuguesa ciudad de Ezqueira, a nueve leguas de Coimbra, vivía un noble que tenía una hija llamada María Pacheco. Llegada a la pubertad, en vez de flujo menstrual le brotó un miembro viril, que no se sabe bien si lo llevaba allí escondido, o si le nació de alguna otra manera. De esta suerte, la muchacha cobró aspecto de mancebo adolescente. Como cuadraba a su sexo, se vistió de hombre y se empezó a llamar Manuel Pacheco. Embarcándose pasó a las Indias, donde por sus hazañas cobró fama de valiente soldado, y también hizo fortuna. De vuelta a su patria, casó con ricahembra. Amado nada dice de que tuviesen descendencia, pero sí que fue siempre imberbe, y de rasgos un tanto afeminados: indicios estos de virilidad imperfecta ${ }^{1}$.

Al leer este relato es casi inevitable sentir sorpresa, estupor y una cierta perplejidad. El desconcierto aumenta al descubrir que el caso de María Pacheco fue conocido y difundido en los Siglos de Oro, especialmente entre médicos, filósofos, teólogos e inquisidores. Llama la atención la naturalidad con que se toma el suceso, como si fuera algo cotidiano y normal. No existe el mínimo atisbo de asombro o escándalo. Todo lo contrario. Parece como si el cambio de sexo fuera una realidad reconocida y admitida en esta época. La curiosidad crece al descubrir que no es un hecho único o aislado, sino que aparte de María Pacheco también existen otros ejemplos como los de Elena de Céspedes, María Muñoz, Francesca y Carola Guarna, Filotis de Esmirna, Eteta de Laodicea, etc. Y resulta un tanto revelador que el relato de sus transmutaciones aparezca intercalado a lo largo de un discurso muy concreto, el que sobre magia escriben hombres como Martín del Río, Juan Eusebio Nieremberg, Francesco Maria Guaccio, Ambroise Paré, Cocceio Sabellico, Antonio de Torquemada, entre otros muchos ${ }^{2}$.

Esta metamorfosis suscita bastantes dudas, algunas de las cuales vamos a intentar resolver a partir de los cuentos que sobre transexualizaciones aparecen intercalados a lo largo de tratados de magia, publicados en la Europa de los siglos XVI y XVII. Comenzaremos precisando el concepto que en estos relatos se tiene del sexo desde el punto de vista biológico.

1. Martín del Río, Disquisitionum magicarum libri VI, Lyon, Horacio Cardon, 1612, liber II, quaestio XXII, fol. 94, col. B. La traducción al español ha sido tomada de la edición realizada por Jesús Moya, Madrid, Hiperión, 1991, p. 392-3.

2. Sobre el cuento inserto en tratados que versan sobre magia, brujería y demonología en la Europa de los siglos XVI y XVII, sus características, su función y su finalidad, se recomienda consultar: María Jesús Zamora Calvo, Ensueños de razón. El cuento inserto en tratados de magia (Siglos XVI y XVII), Madrid/Frankfurt, Iberoamericana/Vervuert, 2005. 
Analizando el corpus de narraciones que hemos recopilado apuntaremos una tipología de la transexualización en estos textos. Para estudiar estos casos es necesario examinar los cambios que experimenta el cuerpo a la hora de transmutarse. Descubrimos entonces que la mayor parte de las metamorfosis se producen de mujer a hombre, mientras que las contrarias resultan excepcionales. Por esta razón se hace necesario buscar la causa que explique estos cambios unidireccionales recurriendo a otros discursos -clásico, teológico, filosófico, médico y jurídico-y analizar si estos enfoques coinciden con el del cuento inserto en tratados de magia.

Hasta la segunda mitad del siglo XVIII no se diferenciaban dos sexos biológicos en el ser humano. Desde la Antigüedad grecolatina hasta los inicios de la Ilustración sólo existía un sexo perfecto, el masculino, mientras que el femenino era tomado como una variación defectuosa de este sexo unitario $^{3}$. Sin embargo entre estos dos extremos (varón versus hembra) se admitía un continuum de formas intermedias donde se localizaban: las mujeres varoniles, los hombres afeminados, los varones menstruantes, los machos que parían ${ }^{4}$, las mujeres barbadas y peludas, los hermafroditas de diverso tipo, etc. Por lo tanto el género sexual con el que se nacía no era determinante para el resto de la vida. Podía cambiar.

En los Siglos de Oro el sexo biológico no marca de manera definitiva el comportamiento social del individuo, es decir, el rol de varón o de hembra no descansa en diferencias biológicas sino en el papel de género. Por ello cuando una mujer cambiaba las actividades propias de su condición, desempeñando trabajos que suponían un gran esfuerzo físico o vistiéndose como un hombre, entonces podía alterar su lugar dentro de esta concepción sexual única, pasando de mujer a varón y con ello mejorando su identidad. En esta época se consideraba posible el cambio de sexo, ya que era tomado como algo natural, frecuente y admitido, un accidente dentro de la jerarquización sexual ${ }^{5}$.

3. En 1990 Thomas Laqueur inagura una nueva etapa en la historia cultural de la construcción de la identidad sexual al publicar Making sex. Body and gender from the greeks to Freud, Cambridge, Harvard University Press, 1990. Partiendo de premisas teóricas foucaultianas, Laqueur sostiene que la división sexual binaria entre varón y hembra es una construcción cultural elaborada en Occidente a partir del siglo XVIII. Cf. Michel Foucault, Historia de la sexualidad, ed. Julia Varela y Fernando Álvarez-Uría, Madrid, Siglo XXI, 2005.

4. Cf. François Delpech, «La patraña del Hombre Preñado: algunas versiones hispánicas», Nueva Revista de Filología Hispánica, 34 (2)1985-1986, p. 548-98; y Sherry M. Velasco, Male delivery: reproduction, effeminacy, and pregnant men in Early Modern Spain, Nashville, Vanderbilt University Press, 2006.

5. Esto no significa que se pudiera escoger libremente un determinado sexo, ya que 
Esta mentalidad, como ya hemos indicado, no es propia de la Edad Moderna sino que hunde sus raíces en la Antigüedad ${ }^{6}$. En la mitología grecolatina Ifis constituye un ejemplo de transexualidad de mujer a hombre. Ovidio ${ }^{7}$ relata esta historia en sus Metamorfosis donde cuenta que, siguiendo el consejo de la diosa Isis, la madre de Ifis oculta el sexo de su hija a su marido cuando esta nace. Por lo tanto la niña es educada como varón. El problema surge cuando, al llegar a la adolescencia, esta se enamora de Yante y, para que pueda casarse con ella, la diosa la transforma en hombre ${ }^{8}$. Otras figuras míticas también experimentaron un cambio en su sexo, tal es el caso de Tiresias quien sorprendió a dos serpientes mientras se apareaban y, al matar a la hembra, quedó convertido en mujer. Siete años más tarde, en circunstancias similares, aplastó al macho y recobró su sexo primitivo. Semejantes metamorfosis experimentaron Hipermestra, Leucipe y Sipretes 9 .

Por otra parte, en la antigua Roma gozaron de cierta reputación las gallae consagradas a la diosa Cibeles. Se les permitía elegir su propio género. Cuando se trataba de hombres que decidían vivir como mujeres se les sometía a una operación quirúrgica, tras la cual mostraban públicamente sus genitales extirpados. Si durante este rito alguien los recibía como regalo se le consideraba bendito. A partir de ese momento se producía el cambio

el orden que se había establecido dentro de esta sociedad estaba basado en la graduación dentro del sexo único. La disciplina social se ocupaba de infundir estas diferencias y de perseguir infracciones como el travestismo. Éste sólo estaba autorizado en los carnavales y mascaradas castigándose en el resto de los casos. Cf. Rudolf D. Dekker y Lotte C. van de Pol, The tradition of female transvestism in Early Modern Europe, New York, St. Martin Press, 1989; Francisco Vázquez García, «La imposible fusión. Claves para una genealogía del cuerpo andrógino», en Diego Romero de Solís, Juan Bosco Díaz-Urmeneta y Jorge López Lloret (eds.), Variaciones sobre el cuerpo, Sevilla, Universidad de Sevilla, 1999, p. 224-5; y Andrés Moreno Mengíbar y Francisco Vázquez García, «Hermafroditas y cambios de sexo en la España Moderna», en Antonio Lafuente y Javier Moscoso, Monstruos y seres imaginarios en la Biblioteca Nacional, Madrid, Biblioteca Nacional, 2000, p. 91-103.

6. Cf. V. C. Bullogh, «Transsexualism in History», Archives of sex behaviour, 4 (1975), p. $561-71$.

7. Ovidio, Metamorfosis, ed. Antonio Ruiz de Elvira, Madrid, Consejo Superior de Investigaciones Científicas, 2002, IX, p. 666-797.

8. Sobre los casos de cambio de sexo en el mito se recomienda consultar: P. M. C. Forbes Irving, Metamorphosis in Greek Myths, Clarendon, Oxford classical monographs, 1990; G. F. Osmun, "Changes of sex in Greek and Roman mythology», The Classical Bulletin (abstracts, bibliographies and history of classical scolarship worldwide) 54 (1977-8), p. 75-9; y Yves Bonnefoy (dir.), Diccionario de las mitologías. Grecia, trad. Maite Solana, Barcelona, Destino, 1996, t. II.

9. Cf. Antonino Liberal, Metamorfosis, ed. Esteban Calderón Dorda, Madrid, Gredos, 1990. 
de identidad, era tratada como a cualquier mujer y se le regalaba un ajuar. Otro testimonio nos lo da Luciano en sus Diálogos de las cortesanas, donde en medio de una conversación lésbica entre Megila y Leena se comenta lo siguiente:

«No -contestó- yo soy completamente varón». «A Ismenodora -le dije- la flautista beocia, en una ocasión en que refería cosas de su tierra, la oí contar que en Tebas una mujer se transformó en hombre, y fue un excelente adivino, creo, de nombre Tiresias. ¿No será, entonces, que a ti te ha ocurrido algo parecido?». "No, ¡qué va, Leena! -respondió- yo nací igual que el resto de vosotras, pero mi forma de pensar, mis deseos y todo lo demás son de hombre». ¿Te basta entonces con tus deseos?» -le pregunté. «Entrégate pues, Leena, si no lo crees -me respondió- y te darás cuenta de que no me falta nada que tengan los hombres, porque tengo una cosa en lugar de miembro viril ${ }^{10}$.

La medicina clásica estableció que sólo existía un único sexo en las personas, un sexo que se manifestaba de dos formas diferentes: la masculina y la femenina, dependiendo de si los órganos se encontraban en el exterior del cuerpo o en el interior ${ }^{11}$. Por lo tanto sólo había dos géneros que marcaban la diferencia social. Se creía que los genitales masculinos eran iguales a los femeninos y que dependía de los humores su localización corporal. La frialdad femenina -sobre todo durante la gestación- provocaba la contracción de los órganos hacia su interior. El caso contrario ocurría en los varones, cuyos genitales salían al exterior a consecuencia de su mayor energía vital. Si, tal y como mantuvo Galeno ${ }^{12}$, todo dependía del calor y de la fuerza expulsiva del organismo, las transexualizaciones por lo tanto eran posibles.

El hombre [...] no difiere de la mujer sino en que tiene los genitales fuera del cuerpo. Porque, haciendo anatomía de una doncella, hallaremos que tiene dos testículos, dos vasos de simiente y la madre, con la misma compostura del miembro

10. Luciano, Diálogos de las cortesanas, ed. Francisco García Yagüe, Madrid, Aguilar, 1972, V, p. 3-6.

11. Cf. Danielle Jacquart y Claude Alexandre Thomasset, Sexualité et savoir médical au Moyen Âge, Paris, Presses Universitaires de France, 1985; Richard L. Kagan and Abigail Dyer, Inquisitorial inquiries: brief lives of secret jews and other heretics, Baltimore/London, The Johns Hopkins University Press, 2004; y Paul Julian Smith, The body hispanic. Gender and sexuality in Spanish and Spanish American Literature, Oxford, Clarendon Press, 1992.

12. Claudio Galeno, Libri duo de semine, Parisiis, apud Simonem Colinaeum, 1533. 
del hombre. Por lo cual, si en acabando naturaleza de fabricar un hombre perfecto, le quisiese convertir en mujer, no era menester más que volverle adentro los instrumentos de la generación. Y si, hecha mujer, la quisiese volver en varón, con echarle la madre y testículos fuera estaba hecho ${ }^{13}$.

El pensamiento médico renacentista aceptaba sin ningún reparo el cambio de sexo de mujer a hombre, ya que ello implicaba una mejora en la naturaleza. Para respaldar dicho argumento se hacía eco de la opinión de Aristóteles (De generatione animalium) ${ }^{14}$ y de Plinio (Historia naturalis) ${ }^{15}$. Además desde el punto de vista teológico, se creía que al final del mundo tanto los hombres como las mujeres resucitarían en el estado más perfecto de su creación, es decir, en figura masculina:

Es de notar que la mujer es de menos dignidad que el varón y ha movido a algunos dotores esta duda. [...] La razón que les hizo dubdar de esto que en la gloria serán los bienaventurados sin alguna fealdad personal y que parescen en la mejor figura que se pueda, y como en la especie humana la mayor perfección sea la del varón, síguese que las mugeres perderán su forma, serán restituidas a la mayor dignidad y nobleza de la especie humana, que es la de varón ${ }^{16}$.

Casi todos los casos de cambio de sexo del femenino al masculino se originan en idénticas circunstancias. Algunos suceden en la primera menstruación: en lugar de producirse la hemorragia se expulsan los genitales masculinos, posteriormente crece la barba y se oscurece la voz. Así le sucedió a María Pacheco. La transformación también puede ocasionarse en la misma noche de bodas, tal y como relata Plinio, quien asegura conocer a L. Cosicio, vecino de Tisdrita, que cuando iba a ser desvirgada se masculinizó, «vivibatque cum proderem haec» ${ }^{17}$. En Ebolia una joven, tras cuatro ańos de noviazgo, quiso desposarse con su prometido. Cuando fue a consumar el matrimonio

13. Juan Fragoso, Erotemas chirvrgicos en los quales se enseña todo lo necessario del arte de cyrugia, Madrid, Pierres Cosin, a costa de Sebastián Yuañez, 1570.

14. Aristóteles, Reproducción de los animales, trad. Ester Sánchez Millán, Madrid, Gredos, 1994.

15. Plinio, Historia natural, ed. Antonio Fontán y Ana Ma Moure, Madrid, Gredos, 1995.

16. Francisco de Eiximenisc, Carro de las donas, trata de la vida y muerte del hombre christiano, Valladolid, Juan de Villaquirán, 1542, cap. XIII, fol. 29.

17. Cita extraída de Martín del Río, op. cit., liber II, quaestio XXII, fol. 94, col. A. 
se le rasgaron las membranas que le daban apariencia de mujer y le salieron órganos viriles. Cambió su identidad por la de varón y reclamó la devolución de su dote ${ }^{18}$. A Filotis de Esmirna le nació un miembro viril cuando fue entregada en matrimonio por sus padres y se convirtió en varón ${ }^{19}$. Esto también ocurrió en Laodicea, una ciudad cercana a Siria, donde Eteta, pese a transexualizarse y pasar a llamarse Eteto, siguió viviendo con su marido ${ }^{20}$.

Se creía que bailar exaltadamente podía provocar que salieran al exterior los órganos sexuales de la mujer, transmutándose de este modo en varón. Esto le sucedió a María de Vitriaco:

Miguel Montano afirma que en su tiempo hubo en Vitriaco una joven llamada María. En cierta ocasión, mientras bailaba con frenesí, le brotaron de pronto órganos viriles y se convirtió en varón. Al recibir el sacramento de la confirmación de manos del Obispo de Soissons le cambiaron el nombre por el de Germán. Más tarde le nació barba, y vivió hasta una edad muy avanzada. Sin embargo, nunca se casó. El autor lo achaca a fuerza de la fantasía; pero yo digo que también debió influir la tendencia de su condición física ${ }^{21}$.

En otros casos las transformaciones podían deberse al deseo de la mujer de ser hombre, es decir, a la fuerza imaginativa y al anhelo vehemente de convertirse en varón. En este sentido el caso más famoso lo narra Antonio de Torquemada en su Jardín de flores curiosas, al acordarse de una mujer castellana que abandonó al marido porque la maltrataba, se vistió de hombre y...

\begin{abstract}
...estando así, o que la naturaleza obrase en ella con tal pujante virtud que bastase para ello, o que la imaginación intensa de verse en el hábito de hombre tuviese tanto poder que viniese a hacer el efecto, ella se convirtió en varón, y se casó con otra mujer ${ }^{22}$.
\end{abstract}

18. Francesco Maria Guaccio, Compendium maleficarum. Ex quo nefandissima in genus humanum opera venefica, ac ad illa vitanda remedia conspiciuntur, Milano, Collegio Ambrosiano, 1624, liber I, cap. XVII, p. 109.

19. Martín del Río, op. cit., liber II, quaestio XXII, fol. 94, col. A.

20. Ibidem.

21. Ibidem, col. B. La traducción al español ha sido tomada de la edición realizada por Jesús Moya, op. cit., p. 394.

22. Antonio de Torquemada, Jardín de flores curiosas, Obras completas, ed. Lina Rodríguez Cacho, Madrid, Turner-«Biblioteca Castro», 1994, t. I, p. 597. 
La auctoritas adquiere una gran importancia en estos relatos ya que da veracidad a lo narrado. De este modo, Antoine Loqueneux, recaudador de tallas reales en Saint-Quentin, aseguró a Ambroise Paré que había visto a un hombre en la Casa del Cisne de Reims que había sido mujer hasta los catorce años...

...pero hallándose jugando y retozando, acostado con una sirvienta, sus partes genitales de hombre se desarrollaron. Su padre y su madre, al reconocerlo como tal, le hicieron cambiar el nombre de Juana por el de Juan, en virtud de la autoridad de la Iglesia, y se le entregaron prendas de varón ${ }^{23}$.

El mismo Ambroise Paré conoció a Germán Garnier, un joven robusto, de constitución fuerte y con una barba bastante poblada, el cual fue mujer hasta los quince años. A esa edad, mientras perseguía a unos cerdos, saltó una zanja. Justo en ese momento se le rompieron los ligamentos dejando al descubierto «los genitales y la verga viril [...] cosa que le ocurrió no sin dolor» ${ }^{24}$. Tras ser revisado por médicos y cirujanos, estos determinaron que era un hombre, por lo que pasó a llamarse Germán, «creo que su madre y él aun viven» ${ }^{25}$.

En otras ocasiones, es un esfuerzo repentino y momentáneo el que desencadena la transexualización de mujer a hombre. Esto fue lo que ocurrió a María Muñoz. Esta mujer perteneciente a la nobleza ingresó en un convento de Úbeda en 1605 obligada por su padre, quien no la consideraba apta para el matrimonio por sus modales varoniles. Después de doce ańos María experimentó una transformación en su cuerpo; mientras transportaba un saco de trigo bastante pesado, sintió un fuerte desgarro en la ingle saliendo de ella un pene con sus respectivos testículos. Tuvo miedo de contárselo al resto de las hermanas de la congregación porque pensaba que lo que realmente había perdido era su virginidad.

Incluso antes de la aparición del pene la virilidad de María había llamado la atención del resto de las monjas, quienes la observaban incluso mientras dormía, descubriendo en su cuerpo y carácter rasgos masculinos porque «sus fuerzas y ánimo y las propiedades y condiciones eran de varón» ${ }^{26}$. Esta tensión se prolongó hasta que María confesó a fray Agustín de Torres

23. Ambroise Paré, Monstruos y prodigios, trad. Ignacio Malaxecheverría, Madrid, Siruela, $1993^{2}$, p. 42.

24. Ibidem.

25. Ibidem.

26. Fray Agustín de Torres, Cartas, BNE-mss. 2058, fol. 258. 
que era "tan hombre como el que más» ${ }^{27}$ y que «jamás le había venido su mes y porque las monjas no le llamasen marimochacho que quando se desciplinaba hacía obstentación de la sangre en las camisas diciendo estaba con su regla» ${ }^{28}$. Cuando el fraile se percató de que a María le habían crecido genitales masculinos ${ }^{29}$ y que su tono de voz se había hecho más grave, pidió que la encerraran en una celda manteniéndola aislada del resto de la comunidad. Poco después María fue proclamada varón ${ }^{30}$, ante lo cual su padre se sintió...

...muy contento porque es hombre rico y no tenía heredero y ahora se halla con un hijo muy hombre y que se puede casar, ella también va contenta porque después de doce años de cárcel sabe muy bien la libertad y se halla de mujer a varón que en las cosas y bienes temporales ninguna merced mayor le pudo hacer naturaleza ${ }^{31}$.

Era tan frecuente que los cambios de sexo se produjeran en los conventos femeninos que el Canon jurídico tuvo incluso que actualizarse promulgando leyes destinadas a reglamentar el estatuto religioso y social del transexual. Martín Navarro de Azpilcueta en su Código de derecho teológico da una serie de reglas canónicas para los diferentes casos que se presentaron en conventos o en el ejército, indicando que les estaba prohibido ejercer ambas profesiones sin permiso del Papa o del Rey ${ }^{32}$.

Por último, la metamorfosis podría sobrevenir tras un parto dificultoso en el que, como consecuencia del esfuerzo realizado, los genitales femeninos

27. Ibidem.

28. Ibidem, fol. 259.

29. «...lo vimos con los ojos y palpamos con las manos y hallamos ser hombre perfecto en la naturaleza de hombre». Ibidem, fols. 258v-9.

30. Este caso gozó de un gran conocimiento y difusión en la España de los Siglos de Oro. Entre los que divulgaron la noticia se encuentra Pedro de Peramato que en su Opera medicinalia de 1576 menciona el cambio de sexo de una monja de Santo Domingo el Real con las mismas características que María Muñoz. Otro médico, Francisco Torreblanca Villalpando recuerda lo ocurrido en el mismo convento de Úbeda, pero la monja que cita se llama Magdalena Muńoz, aunque la alternancia de los nombres María y Magdalena era frecuente en esta época. Cf. Pedro de Peramato, Opera medicinalia, Sanlúcar de Barrameda, Fernández Díaz, 1576, fol. 116; y Francisco Torreblanca Villalpando, Epithomes delictorum in quibus aperta vel occulta invocatio daemonis intervenit, Sevilla, Ildeso Rodríguez Gamarra y Francisco de Lira, 1618, liber II, cap. XVII, fol. 104, col. 5.

31. Fray Agustín de Torres, op. cit., fol. 259.

32. Martín Navarro de Azpilcueta, Nvnc primvm in vnvm qvasi corpus coagmentati [...] capitum Juris Canonici expositum \& legum Juris civilis, Lugduni, Haer. Gvliermi Rovillii, 1591. 
tomaban la posición masculina, tal y como ocurrió en Alcalá de Henares a una mujer de unos treinta ańos que al dar a luz «mejoró de sexo» ${ }^{33}$. Pero, sin lugar a dudas, el relato más famoso y que mayor repercusión tuvo en Europa fue el protagonizado por Elena de Céspedes, de ahí que le dediquemos una atención especial.

En la Ocaña de 1587 un rumor hizo saltar el escándalo sobre la verdadera identidad sexual de Eleno de Céspedes. Se dudaba si era hombre o mujer, lo que puso en entredicho la legalidad de su matrimonio con María del Caño. Tanto se murmuró al respecto que las autoridades de la zona decidieron investigar este caso en un proceso celebrado por el Tribunal del Santo Oficio de Toledo. Detuvieron a Céspedes acusándolo de sodomía, bigamia, hacerse pasar por hombre, burlarse del sacramento del matrimonio y tener pacto con el demonio ${ }^{34}$. En la primera audiencia con el inculpado, éste afirmó que fue bautizado como mujer en Alhama (Granada) y que nunca notó nada ajeno a su condición femenina. Incluso se casó, a instancia de sus padres, con Cristóbal de Lombardo cuando contaba unos dieciséis años. Pero...

...cuando esta parió como tiene dicho con la fuerza que puso en el parto se le rompió un pellejo que tenía sobre el caño de la orina y le salió una cabeza como medio dedo pulgar [...] que parecía en su hechura cabeza de miembro de hombre. El qual quando esta tenía deseo y alteración natural le salía como dicho tiene ${ }^{35}$.

Después de esta transexualización se sintió hombre, se desentendió de su hijo y empezaron a atraerle mujeres como Ana de Albánchez, a la que un día «le vino gana de besarla y sin decirle cosa alguna la besó y espantada se dejó ella, esta le dijo que podría tener con ella cuenta como hombre» ${ }^{36}$.

33. Juan Eusebio Nieremberg, Cvriosa filosofia y tesoro de maravillas de la naturaleza, examinadas en varias cuestiones naturales, Madrid, Imprenta del Reino, 1630, liber II, cap. XVII, fol. 64v-5.

34. Proceso Inquisitorial de Elena o Eleno de Céspedes, Archivo Histórico Nacional de Madrid, Inquisición, Leg. 234, $\mathrm{n}^{\circ}$ 24. Sagrario Muñoz Calvo realiza una transcripción parcial del proceso, estudiándolo desde un punto de vista médico en el Boletín de la Sociedad Española de Historia de la Farmacia 93 (1973), p. 20-33. Un examen más detallado de este caso lo encontramos en Michèle Escamilla, «À propos d'un dossier inquisitorial des environs de 1590: les étranges amours d'un hermaphrodite», en Augustin Redondo (dir.), Amours légitimes, amours illégitimes en Espagne (XVI-XVII siècles), Paris, Sorbonne, 1985, p. 167-82.

35. Proceso Inquisitorial de Elena o Eleno de Céspedes, op. cit., fol. III.7, declaración del 17 de julio de 1587.

36. Ibidem, fol. III.6v, declaración del 17 de julio de 1587. 
Un cirujano le liberó el pene por completo, decidió vestirse de hombre y adquirir plenamente su nueva identidad, llegando incluso a alistarse como soldado en las campañas contra los moriscos de Granada. Viajó por varias localidades andaluzas y manchegas, incluso en Madrid llegó a obtener el título de cirujano y sangrador. Se hizo llamar Céspedes y decidió casarse con María del Caño. Pero al solicitar la licencia matrimonial el Vicario de Madrid dudó sobre su naturaleza sexual, por lo que tuvo que pasar hasta tres exámenes realizados por distintos médicos. Ante esta situación ¿pudo hacer uso de sus conocimientos médicos para disimular la vagina con unos emplastos? ¿Consiguió atribuir la hendidura vaginal a las cicatrices producidas por una operación de hemorroides? ¿Logró burlar la revisión de médicos tan eminentes como Francisco Díaz ${ }^{37}$ y Antonio Mantilla? Pues parece ser que sí, porque obtuvo la autorización para casarse.

A lo largo de la audiencia Céspedes aseguró que sus genitales masculinos funcionaban con toda regularidad en cuanto a orina, poluciones y tamaño se refiere. Sin embargo, cuando el Tribunal le pidió que se los mostrara, confesó que sufría una enfermedad a causa de la cual «se le enmustió el dicho miembro volviéndosele como de esponja y esta la fue cortando poco a poco de manera que ha venido a quedar sin ello» ${ }^{38}$. De repente, su órgano sexual masculino había desaparecido a causa de un supuesto cáncer. ¿Cómo es posible esto? ¿A qué se debe esta repentina transexualización? A estas alturas el Tribunal comenzó a sospechar que todo se trataba de una falacia y que Céspedes nunca dejó de ser mujer. Pero entonces ¿cómo se explica que mantuviera relaciones sexuales plenas con su mujer tal y como ésta declaró ante el Santo Oficio? Según Lisa Vollendorf, es probable que utilizara un juguete sexual para penetrar a María del Caño, un consolador realizado en madera. "At the time, female sodomy was defined as women using implements to impersonate men during sex» ${ }^{39}$.

Cuando el Tribunal de la Inquisición llamó a los dos médicos que examinaron a Céspedes para dictaminar si realmente era un varón, les pidió que de nuevo realizaran una inspección detallada del encausado. La sorpresa saltó cuando descubrieron que no solo se trataba de una mujer con todos sus órganos, sino que incluso no quedaba la menor huella de haber sido anteriormente hombre; no encontraron ni cicatrices, ni señales

37. Francisco Díaz fue médico y cirujano de Su Majestad, el mayor especialista en urología en la España de finales del siglo XVI, autor del Tratado [...] de todas las enfermedades de los riñones, vexiga y carnosidades de la verga y urina, Madrid, Francisco Sánchez, 1588.

38. Proceso Inquisitorial de Elena o Eleno de Céspedes, op. cit., fol.I.45.

39. Lisa Vollendorf, The lives of women. A new history of inquisitional Spain, Nashville, Vanderbilt University Press, 2005, p. 18. 
de desprendimiento genital, ni signos de que la vagina hubiera estado alguna vez cerrada. ¿Cómo se explica este cambio fisiológico en un individuo? Obviamente, la mentalidad premoderna lo atribuyó a una clara intervención del demonio. El diablo cegó la vista de los médicos para que vieran lo que realmente no era. Valiéndose de su ilusionismo convirtió temporalmente un órgano sexual femenino en otro masculino. Finalmente el Santo Oficio de Toledo declaró que se trataba de un fraude, acusando a Elena de Céspedes de bigamia, porque aunque proclamó ante la audiencia que su marido había muerto, no se encontró certificado alguno que lo probara, por lo que la condena se fijó en doscientos azotes y diez años de trabajo forzado en un hospital ${ }^{40}$.

En definitiva, Elena fue una mujer que llevada por su deseo de vivir de forma independiente y libre decidió hacerse pasar por varón. Esta determinación la llevó hasta sus últimas consecuencias: travistiéndose y actuando como hombre, ocultando por completo su feminidad, mostrando unos genitales masculinos tan bien fingidos que engañaron a varios médicos y, por último, casándose con María del Caño. Lo que más sorprende es cómo una mujer, de origen morisco y esclavo, sin educación formal, llegó a ejercer como cirujano. Es posible que ahí resida la clave por la que Elena creó su propia historia de cambio de sexo. Tal y como revela su biblioteca personal, supo todo lo relativo al dimorfismo sexual de su época. A través de estos libros pudo documentar y dar verosimilitud a la ficción de su identidad, es decir, usó dichos conocimientos en su favor y en contra de una sociedad que la relegaba por su condición de mujer a la pasividad, el esclavismo y la inevitable inexistencia ${ }^{41}$.

Como se ha podido comprobar, los relatos de transexualización más frecuentes son aquellos en los que se narra el cambio de mujer a hombre, sin embargo, también se registran algunos casos contrarios, tal y como refiere Martín del Río en el siguiente pasaje:

Quid si et Salmacis fons maleficum quid habuerit iniectum? Sane, quod Strabo de illo refert [...] ex eo bibentes malacisari, id ego non tam ad mutationem in hermaphroditos, quam

40. Al poco tiempo de estar en el hospital, su director pidió al Santo Oficio el traslado urgente de Elena, ya que la gente acudía a ella en masa para que les curara. Lo mismo ocurrió en el hospital de San Lázaro y es que en esta época la creencia popular otorgaba determinados poderes mágicos a personas ambiguas sexualmente. Cf. Francisco Vázquez García y Andrés Moreno Mengíbar, Sexo y razón. Una genealogía de la moral sexual en España (Siglos XVI y XX), Madrid, Akal, 1997.

41. Cf. Marie-Catherine Barbazza, «Un caso de subversión social: el proceso de Elena de Céspedes (1587-1589)», Criticón, 26 (1984), p. 17-40. 
ad emasculationem, et (ut Varro loquitur, alio tamen sensu) mulierationem retulerim. Haec enim hominibus illis a Christi lege et fide alienis, quasi necessaria consecutio (nefas!) videbatur, ut qui agere nequiret, pati inciperet. Beneficium hoc inter cetera fidei Christianae non minimum; quod cum daemonum cultu portentosa haec daemonum suasu et hortatu crimina paganismo inolita, tandem plerisque, in regionibus prorsus exoleuerint ${ }^{42}$.

La medicina clásica también explica dicha transformación a partir de la teoría humoral. Huarte de San Juan, en su Examen de ingenios opina que:

...muchas veces tiene Naturaleza hecho un varón, con sus miembros genitales afuera, y sobreviniendo frialdad, se les vuelven adentro; y queda hecha hembra. Conócese después de nacida en que tiene el aire de varón, así en el habla como en todos sus movimientos y obras ${ }^{43}$.

Sin embargo estos ejemplos arremeten contra la idea aristotélica de que la naturaleza tiende a la perfección, es decir, la mujer podía «mejorar de sexo» convirtiéndose en hombre. La posibilidad inversa transgredía por completo el orden del cosmos dispuesto por Dios. Para Aristóteles era evidente la superioridad de lo masculino sobre lo femenino. Según él, las hembras no eran más que machos defectuosos al recibir poco calor durante su gestación. Las transmutaciones tienen que operar en el sentido ascendente, pero nunca descendente. Si esto último se produjera sólo podría explicarse a través de una alteración diabólica de la percepción ${ }^{44}$.

Desde el punto de vista cultural el rechazo que sufrió la transexualización en el Siglo de las Luces se debió al cambio de mentalidad que tuvo lugar en el mundo occidental. Se empieza a esbozar una nueva teoría del conocimiento donde la experiencia es la única llave del intelecto. Comienza a desvanecerse la imagen de un universo concebido como una entidad animada, en la que el hombre es prisionero de una fina tela de araña donde las influencias e interrelaciones invisibles marcan el destino de su existencia. En estas décadas se asienta la base de las nuevas ciencias experimentales donde las leyes que

42. Martín del Río, op. cit., liber III, pars I, quaestio IV, sectio VIII, p. 186, col. B.

43. Juan Huarte de San Juan, Examen de ingenios, ed. Guillermo Serés, Madrid, Cátedra, 1989 , p. 609.

44. Cf. Fernando Álvarez-Uría, «Razón y pasión. El inconsciente sexual del racionalismo moderno", en Fernando Savater, Filosofía y sexualidad, Barcelona, Anagrama, 1988, p. 110-7. 
rigen la naturaleza se enfocan desde un punto de vista racional. Estas normas son las que marcan los límites de lo posible y excluyen los prodigios y las maravillas. Las transexualizaciones se rechazan tomándolas como meras supercherías, producto de la ignorancia de un pueblo iletrado.

Es ahora cuando el sexo biológico marca la identidad genérica de un individuo ${ }^{45}$. Pero detrás de esta diferenciación se esconde una estrategia política. El transfuguismo de género era común entre los nobles, donde los papeles masculino y femenino no se hallaban perfectamente diferenciados y donde la mujer disponía de un poder incluso superior al del hombre. Con el discurso del "sexo verdadero" y del modelo dual se fijan y se separan las identidades sociales expulsando a las mujeres de la vida pública. Con ello la burguesía definió una identidad basada en la virilidad de su carácter frente al afeminamiento de la aristocracia ${ }^{46}$. Poder y sexo unidos una vez más. En una época en la que la razón devoró todo lo que no pasara por el filtro de su entendimiento, el transexual perdió su verdadera condición para convertirse en un monstruo al que había que castigar y curar. Tendrán que pasar varios siglos para que el género comience a identificarse con su propio sexo.

Y para terminar, queda en el aire esta curiosa paradoja: la transexualización en la época áurea-un fenómeno hasta el momento poco estudiado-es asumida con enorme tolerancia, respeto y aceptación social a pesar de desarrollarse en una sociedad altamente sacralizada y regida por valores religiosos. Sin embargo, cuando la anomalía biológica abandona los cauces del mundo sometido a un orden divino pasa a ser repudiada y marginada. Como telón de fondo permanece este ideal que aboga por una diferenciación sexual de raíz neoplatónica. Esta concepción quedó plasmada en el imaginario que describen obras como el Rosarium philosophorum ${ }^{47}$ a través de un complejo proceso alquímico, pensamiento que se desliza a lo largo de los siglos hasta llegar a nuestros días en defensa de otra imagen del cuerpo.

45. En el siglo siguiente, el XIX, es cuando más atención se presta al hermafroditismo a partir del descubrimiento de la función ovárica. Cf. Anne Fausto-Sterling, Sexing the body: gender politics and the construction of sexuality, New York, Basic Books, 2000.

46. Cf. Francisco Vázquez García y Andrés Moreno Mengíbar, Sexo y razón, op. cit.

47. Arnau de Vilanova, Rosarium philosophorum, trad. Joan Borrell, Barcelona, Indigo, 1998. 


\section{Bibliografía}

Álvarez-Uría, Fernando, «Razón y pasión. El inconsciente sexual del racionalismo moderno», en Fernando Savater, Filosofía y sexualidad, Barcelona, Anagrama, 1988, p. 110-7.

Aristóteles, Reproducción de los animales, trad. Ester Sánchez Millán, Madrid, Gredos, 1994.

Barbazza, Marie-Catherine, "Un caso de subversión social: el proceso de Elena de Céspedes (1587-1589)», Criticón, 26 (1984), p. 17-40.

Bonnefoy, Yves (dir.), Diccionario de las mitologías. Grecia, trad. Maite Solana, Barcelona, Destino, 1996, t. II.

Bullogh, V. C., "Transsexualism in History», Archives of sex behaviour, 4 (1975), p. $561-71$.

Delpech, François, «La patraña del Hombre Preñado: algunas versiones hispánicas», Nueva Revista de Filología Hispánica, 34 (2)1985-1986, p. 548-98.

Dekker, Rudolf D. y Lotte C. van de Pol, The tradition of female transvestism in Early Modern Europe, New York, St. Martin Press, 1989.

Díaz, Francisco, Tratado [...] de todas las enfermedades de los riñones, vexiga y carnosidades de la verga y urina, Madrid, Francisco Sánchez, 1588.

Escamilla, Michèle, «A propos d'un dossier inquisitorial des environs de 1590: les étranges amours d'un hermaphrodite», en Augustin Redondo (dir.), Amours légitimes, amours illégitimes en Espagne (XVI -XVII siècles), Paris, Sorbonne, 1985, p. $167-82$.

Eiximenisc, Francisco de, Carro de las donas, trata de la vida y muerte del hombre christiano, Valladolid, Juan de Villaquirán, 1542.

Fausto-Sterling, Anne, Sexing the body: gender politics and the construction of sexuality, New York, Basic Books, 2000.

Forbes Irving, P. M. C., Metamorphosis in Greek Myths, Clarendon, Oxford classical monographs, 1990.

Foucault, Michel, Historia de la sexualidad, ed. Julia Varela y Fernando ÁlvarezUría, Madrid, Siglo XXI, 2005.

Fragoso, Juan, Erotemas chirvrgicos en los quales se enseña todo lo necessario del arte de cyrugia, Madrid, Pierres Cosin, a costa de Sebastián Yuañez, 1570.

Galeno, Claudio, Libri duo de semine, Parisiis, apud Simonem Colinaeum, 1533.

Guaccio, Francesco Maria, Compendium maleficarum. Ex quo nefandissima in genus humanum opera venefica, ac ad illa vitanda remedia conspiciuntur, Milano, Collegio Ambrosiano, 1624.

Huarte de San Juan, Juan, Examen de ingenios, ed. Guillermo Serés, Madrid, Cátedra, 1989. 
Jacquart, Danielle y Claude Alexandre Thomasset, Sexualité et savoir médical au Moyen Âge, Paris, Presses Universitaires de France, 1985.

Kagan, Richard L. and Abigail Dyer, Inquisitorial inquiries: brief lives of secret jews and other heretics, Baltimore/London, The Johns Hopkins University Press, 2004.

Laqueur, Thomas, Making sex. Body and gender from the greeks to Freud, Cambridge, Harvard University Press, 1990.

Liberal, Antonino, Metamorfosis, ed. Esteban Calderón Dorda, Madrid, Gredos, 1990.

Luciano, Diálogos de las cortesanas, ed. Francisco García Yagüe, Madrid, Aguilar, 1972.

Moreno Mengíbar, Andrés y Francisco Vázquez García, «Hermafroditas y cambios de sexo en la España Moderna», en Antonio Lafuente y Javier Moscoso, Monstruos y seres imaginarios en la Biblioteca Nacional, Madrid, Biblioteca Nacional, 2000, p. 91-103.

Navarro de Azpilcueta, Martín, Nvnc primvm in vnvm qvasi corpus coagmentati [...] capitum Juris Canonici expositum \& legum Juris civilis, Lugduni, Haer. Gvliermi Rovillii, 1591.

Nieremberg, Juan Eusebio, Cvriosa filosofia y tesoro de maravillas de la naturaleza, examinadas en varias cuestiones naturales, Madrid, Imprenta del Reino, 1630.

Osmun, G. F., "Changes of sex in Greek and Roman mythology", The Classical Bulletin (abstracts, bibliographies and history of classical scolarship worldwide) 54 (1977-8), p. 75-9.

Ovidio, Metamorfosis, ed. Antonio Ruiz de Elvira, Madrid, Consejo Superior de Investigaciones Científicas, 2002.

Paré, Ambroise, Monstruos y prodigios, trad. Ignacio Malaxecheverría, Madrid, Siruela, $1993^{2}$.

Peramato, Pedro de, Opera medicinalia, Sanlúcar de Barrameda, Fernández Díaz, 1576.

Plinio, Historia natural, ed. Antonio Fontán y Ana Ma Moure, Madrid, Gredos, 1995.

Proceso Inquisitorial de Elena o Eleno de Céspedes, Archivo Histórico Nacional de Madrid, Inquisición, Leg. 234, no 24.

Río, Martín del, Disquisitionum magicarum libri VI, Lyon, Horacio Cardon, 1612. Smith, Paul Julian, The body hispanic. Gender and sexuality in Spanish and Spanish American Literature, Oxford, Clarendon Press, 1992.

Torquemada, Antonio de, Jardin de flores curiosas, Obras completas, ed. Lina Rodríguez Cacho, Madrid, Turner-«Biblioteca Castro», 1994, t. I, p. 495-904. 
Torreblanca Villalpando, Francisco, Epithomes delictorum in quibus aperta vel occulta invocatio daemonis intervenit, Sevilla, Ildeso Rodríguez Gamarra y Francisco de Lira, 1618.

Torres, Fray Agustín de, Cartas, BNE-mss. 2058.

Vázquez García, Francisco y Andrés Moreno Mengíbar, Sexo y razón. Una genealogía de la moral sexual en España (Siglos XVI y XX), Madrid, Akal, 1997.

Vázquez García, Francisco, «La imposible fusión. Claves para una genealogía del cuerpo andrógino", en Diego Romero de Solís, Juan Bosco Díaz-Urmeneta y Jorge López Lloret (eds.), Variaciones sobre el cuerpo, Sevilla, Universidad de Sevilla, 1999, p. 217-36.

Velasco, Sherry M., Male delivery: reproduction, effeminacy, and pregnant men in Early Modern Spain, Nashville, Vanderbilt University Press, 2006.

Vilanova, Arnau de, Rosarium philosophorum, trad. Joan Borrell, Barcelona, Indigo, 1998.

Vollendorf, Lisa, The lives of women. A new history of inquisitional Spain, Nashville, Vanderbilt University Press, 2005.

Zamora Calvo, María Jesús, Ensueños de razón. El cuento inserto en tratados de magia (Siglos XVI y XVII), Madrid/Frankfurt, Iberoamericana/Vervuert, 2005. 
